\title{
Caring for baby: What information channels do mothers use and trust?
}

\author{
Angela Dobele \\ School of Economics, Finance and Marketing, RMIT University, Melbourne, Australia \\ Jane Fry \\ School of Economics, Finance and Marketing, RMIT University, Melbourne, Australia \\ Sharyn Rundle-Thiele \\ Department of Marketing, Griffith University, Nathan, Australia, and \\ Tim Fry
}

School of Economics, Finance and Marketing, RMIT University, Melbourne, Australia

\begin{abstract}
Purpose: A broad array of information channels exist for service customers. If we can better understand the relationship between the use of and trust in information channels, there is scope to increase the effectiveness of reliable information provision and hence to change behaviour.
\end{abstract}

Methodology: This study empirically explored whether customers use channels they trust, and trust what they use, and examined the association between individual (demographic) factors and that trust. A total of 472 mothers completed an online survey.

Findings: The current study empirically explored channel trust and individual factors, finding that individual factors (such as education level) and trust warrant inclusion in traditional communication models such as C-HIP. The findings revealed that the more highly educated a customer is, the more likely it will be that a health professional is their most trusted channel, but the less likely it will be that they consider family the most trusted channel. Magazines are the least trusted information channel. Further, while informants’ most 
trusted information channel was healthcare professionals, this was not the most common information channel used.

Research limitations: This study was limited to a female consumer sample focused upon one service, maternity and child health, and five key information channels, which limits the generalisability of the findings. The data were collected via an Internet survey, which may bias the results on use and trust of the Internet. Additionally, the data were collected over five years ago which may have some impact on factors such as the role and importance of Internet usage. However, these limitations do not detract from the primary focus of this research, and the main findings remain new and relevant. The findings showcase the importance of demographic factors and the relationship between trust in information sources and use. The insights developed, provide a useful research agenda for the future.

Originality/value: This paper undertook an empirical exploration to examine information channel trust and individual factors, thereby extending the research focus beyond current traditional communication model approaches. Models such as C-HIP focus on individual cognitions and assume a staged sequence of decision-making following traditional decisionmaking models and ignoring channel attributes such as channel trust, thereby limiting understanding. The current study indicates that communication models will benefit from the addition of channel trust and additional individual factors (such as demographics) to extend understanding beyond individual cognitions.

Keywords: Healthcare, maternal and child health, credence services, information channels, channel trust.

\section{Introduction}


Information and advice assist people to make informed decisions helping them understand the advantages and disadvantages associated with various choices (Thompson 2013). In relation to services that are high in credence qualities such as maternal health services, it is important that customers choose the service themselves as this can have a positive impact on both the quality of the service delivered and their satisfaction with that service, and can thereby (potentially) improve service outcomes (Rundle-Thiele \& Russell-Bennett 2010). If we can better understand the relationship between the use of and trust in information channels as inputs to such customer decision-making, there will be scope to increase the effectiveness of reliable information provision and limit the effects of misinformation to improve service outcomes.

In gathering information to assist their decision-making, people use a variety of information channels. In the healthcare context, these include allied practitioners; local experts (local laypeople with relevant personal experience); mass media channels, including books and magazines (Cotton \& Gupta 2004); and, increasingly, the InternetInternet. In fact, the InternetInternet currently provides an unprecedented amount of information (Hesse, Nelson, Kreps, Croyle, Arora, Rimer \& Viswanath 2005, Della, Eroglu, Bernhardt, Edgerton \& Nall 2008).

In the past, customers were predominantly viewed as passive recipients of services that are high in credence qualities (Holman \& Lorig 2000, Berry \& Bendapudi 2007) and the highcredence system was characterised by information asymmetry (Deshpande 1983, Payne, Storbacka \& Frow 2008). However, this view is changing: information is becoming of increasing value to customers as it allows them to make better decisions. Further, higher levels of education and growing interest in some service contexts have meant that, in the healthcare context, patients now actively seek health information. 
Further, customer education and management are seen as increasingly important to facilitate partnerships between service providers and consumers. Such partnerships are defined by the service marketing approach which seeks to create a service based on cooperation between customers and service providers (Zainuddin, Russell-Bennett \& Previte 2013), leading to the co-creation of value and service quality (Dobele \& Lindgreen 2011, Zainuddin et al. 2013). Moreover, these changes are occurring in industries that are experiencing growth in both demand and expenditure (Greer, Russell-Bennett, Tombs \& Drennan 2014).

Past research has demonstrated that, in making decisions about healthcare that affect their young children, mothers place the most value on information on personal referrals obtained from personal, rather than professional, channels (Dobele \& Lindgreen 2011). Indeed, these referrals are deemed more important than the professional recommendations of general practitioners or other healthcare professionals (Fisher \& Anderson 1990, Gombeski, Carroll \& Lester 1990, Williams \& Hensel 1991, Murray 1992).

Considered broadly, information sources must be clearly understood because, 'even though patients are nowadays better educated and have improved access to various online information, compared with accessibility a decade ago, seeking health information is still a complex process’ (Otani et al. 2009 and Gaglioa et al. 2012 cited by Martin 2016, n.p.). In order to sift through a variety of health information sources, patients (and those evaluating information on behalf of patients) 'must know the topic of interest, where to look or ask, how to assess and comprehend, and how to evaluate the credibility and trustworthiness of the sources’ (Gaglio, Glasgow \& Bull 2012, p. 19). In summary, information seekers require skills to first source information and then to evaluate and understand this information.

Healthcare is an important service construct insofar as 'it is an enormously expensive, highly complex, universally used service that significantly affects economies and the quality of daily 
living’ (Berry \& Bendapudi 2007, p. 111), and the role of information search behaviors is also important as they affect health behaviors (Martin 2016). In particular, patients increasingly want to contribute in the decision-making undertaken by their healthcare providers as well as the decisions about their medical treatment (Liang \& Scammon 2011, Niehues, Emmert, Haas, Schöffski \& Hamm 2012).

Guided by the Communication-Human Information Processing (C-HIP) Model, this study seeks to examine the relationship between the use of and trust in various information channels in a maternal healthcare context to explore whether mothers use the channels they trust and trust what they use. Further, the role of individual demographic factors is considered in order to extend our understanding of how information is processed by credence service customers.

\section{The role of information in services}

Drawing from communication theory, the C-HIP Model is a framework for structuring the stages involved in the flow of information from a channel to a receiver, who then processes the information, which in turn shapes their behaviour (Conzola and Wogalter, 2001). Within this model, the focus is on understanding individual cognitions, assuming a staged sequence of decision-making following traditional decision-making models (see Lye, Shao, RundleThiele \& Fausnaugh 2005 for an extensive discussion of consumer decision processing models). The C-HIP framework, in line with other communication models such as AIDA (e.g. Elnaga \& Abunayyan 2016), proposes that attention is first required, followed by comprehension which should lead to attitude formation and then motivation, resulting finally in the desired behaviour.

Since the early attempts to understand information usage patterns across service industries (Mitra, Reiss \& Capella 1999), and the development of the first models such as C-HIP 
(Wogalter, DeJoy \& Laughery 1999, Conzola \& Wogalter 2001), online mediums and the range of information channels available to consumers have proliferated (e.g. Jensen, Liu, Carcioppolo, John, Krakow \& Sun 2016 for a summary of the ever-increasing volume of accessible information related to health as one example of this proliferation).

Modern communication technologies make the creation, duplication and dissemination of information both easy and fast. However, the vast quantity of information can make it difficult for consumers to know what is good-quality information, leading to frustration and confusion (Arora, Hesse \& Rimer 2008). The variations in quality may lead to different levels of trust for different channels (Chesney, Chuah, Dobele \& Hoffman 2017).

Prior research indicates that 'it is likely that different categories of information channels (such as direct to consumer marketing) produce different levels of trust, which in turn contributes to information search behaviors in different ways' (Ha \& Lee 2011, p. 21). It is, therefore, crucial to consider 'people's use of information channels as well as their trust in them’ (Pieniak, Verbeke, Scholderer, Brunsø \& Olsen 2007, p. 1060). Trust is especially important given the potential for the misrepresentation of information - particularly on the InternetInternet (Gray, Klein, Noyce, Sesselberg \& Cantrill 2005).

\section{Trust Defined}

Trust refers to ‘a person's expectation that interaction partners will act in a cooperative manner based on shared norms' (Chesney et al. 2017, p. 4). At the micro level, trust is felt from one person to another and can evolve and change (either positively or negatively) throughout the course of a relationship (Mutz 2005). Trust may also be present more generally - for example, within a group of relative strangers (Gefen, Benbasat, \& Pavlou, 2008). 
Trust is a social phenomenon, involving sociological actions and implications (Zaheer \& Venkatraman 1995), and research into trust can, therefore, adopt a variety of perspectives through which such social practice is observed. For example, using a model of human nature predicated upon social interactions, researchers could consider trust as either the function of a rational egoist or as the outcome of a social interaction informed by moral considerations.

Understanding the role of trust in business dealings is complex for two reasons. First, the trust construct is intrinsically complex and 'multifaceted' (Waytz, Heafner \& Epley 2014, p. 113) in nature, which has given rise to a myriad of definitions and possible measurements (Hupcey, Penrod, Morse \& Mitcham 2001, Grabner-Kräuter \& Bitter 2013).

Second, although trust plays an important role in marketing practice, it is difficult to monitor and risky to seek to enhance. Trust is important to retail trade (Toufaily, Souiden, \& Ladhari, 2013), and is a significant and powerful tool for reducing the negative impact of asymmetric information and transaction costs (San Martín \& Camarero, 2005). From the business perspective, trust is fostered through the building of relationships between buyers and sellers, to develop and maintain a loyal customer base (Webster 1992 cited by Tzempelikos \& Gounaris 2017). However, in this scenario, sellers and buyers have different motivations. Customers can gain assistance from a supplier/service provider to make 'better-informed decisions'; yet 'customer trust in and supplier trustworthiness are motivated by conflicting pecuniary incentives’ (Özer, Subramanian \& Wang 2017, n.p.).

An onion cognitive mapping process, (designed to highlight the many layers involved), has helped to provide 'a richer explanation' of trust types and trust in communication scenarios (Cheng, Fu \& de Vreede 2017, p. 33). This type of past research has identified that marketing strategies and tactics were aimed at 'strengthening the customer-supplier relationship, which in turn, builds trust and increases profitability’ (Bennett \& Rundle-Thiele 2004). 


\section{Information channel trust}

Knowledge of the information channels used by consumers during the decision-making process is important to understanding how they gather and organise information and, ultimately, how they make a purchase decision (Alba \& Hutchinson 1987). Consumers can access information from multiple channels, and this may indicate some degree of complementarity in the channels used (Koch-Weser et al. 2010; Rains 2007). For example, 'information obtained from the InternetInternet might be compared ... [with] other channels ... to “cross check” consistency’ (Gray et al. 2005, p. 1473), for reassurance or confirmation (Bikhchandani, Hirshleifer \& Welch 1991, Karrh 2002), or to gather more detailed information (Kostagiolas, Martzoukou, Georgantzi \& Niakas 2013). There is also evidence that the choice of a particular channel, such as the InternetInternet, may be linked to the number of other channels used (Cotton \& Gupta 2004).

To influence decisions, information gathered must be turned into knowledge, as it is not automatically consumed or homogeneously processed' (Thiede 2005, p. 1454). A lack of effective information (and therefore knowledge) can limit the consumer's choice set; and, in this regard, trust is an important antecedent to information effectiveness (Pieniak et al. 2007). In relation to the information channel, 'trust lies at the centre of communicative processes (Thiede 2005, p. 1455), [and] in order [to be used] ... the information transmitted must be considered trustworthy to a certain degree', and consumers use trust as a 'mechanism to make calculations easier' (Bloom, Standing \& Lloyd 2008, p. 2078).

\section{Healthcare information channel use and trust}

Conceptually, the decision to seek professional healthcare (and how much to acquire and where to acquire it) results from patients comparing the perceived benefits with the perceived costs (Álvarez \& Vera-Hernández 2013). Some patients may be largely passive recipients of 
care (Ham \& Alberti 2002). This can be due to a number of factors, including: an entrenched culture that believes that 'doctor knows best' (e.g., in Turkish culture doctors are viewed as authority figures, Kilicarslan-Toruner \& Akgun-Citak 2013) or that health professionals, particularly physicians, are the most trusted channel for health information (Hesse et al. 2005, Dorsey \& Songer 2006). Such a domineering attitude taken by the medical professional (Laing \& Hogg 2002) encourages patients to defer to the opinion of professionals (Neuberger 2000). Another explanation for passively receiving care are situations where the patient has no choice or control, for example, from limited availability of health professionals or access to information and/or services, or from restrictions in the patient's personal finances. Such factors constrain the choice set from which information is sought.

\section{Empowered patients}

In the past decade, patients have shown new levels of empowerment 'by taking an active and informed role in treatment decisions and switching physicians if care is unsatisfactory’ (Harris 2003, p. 711). According to Hesse et al., 'most physicians are ... experiencing the effects of patients showing up to their offices armed with printouts from the World Wide Web and requesting certain procedures, tests or medications' (2005, p. 2619). Further, wider access to information 'increases the likelihood of visiting a physician as well as the frequency of visits on average' (Dwyer \& Liu 2013, p. 1), and health professionals may be required to interpret information for the consumer.

For some consumers, accessing information from elsewhere reduces the reliance on medical professionals and healthcare service providers, and lessens the information asymmetry between healthcare professionals and the patient/customer (Criéa \& Chebatb 2013). Utilising alternative information channels may lead to self-diagnosis, the consumer identifying

additional treatment options or questioning the information provided by healthcare 
professionals. It may also lead 'low-trust consumers ... to substitute self-care through consumer health information for physician services' (2013, p. 1), which may open up the potential for consumers to utilise healthcare services or adopt healthcare practices that are harmful or lack national accreditation, and lead to adverse health outcomes.

To date, communication theory has centered upon conceptualising individual cognitions (for example, see C-HIP as outlined in Conzola and Wogalter, 2001). However, the homogenous treatment of diverse individuals, with unique characteristics, limits understanding. The inclusion of demographic factors (such as age, income, education and number of people in the house) extends understanding beyond psychographic characteristics (such as understanding, attitudes and motivations) and therefore represents a move towards acknowledging the heterogeneity present in the market. Limited research attention directed towards the role played by individual factors (such as demographics) in traditional communication models has resulted in a gap in our understanding.

\section{Individual demographic characteristics}

Previous research has shown the importance of parental educational attainment for health information seeking. For example, Kostagiolas et al. (2013) found that parents with low education levels more frequently used family as information channels, whereas the Internet was used more by parents with higher education levels. Similarly, Hesse et al. (2005) found that people with higher education levels had more trust in the Internet and magazines than did those with lower education levels. Higher levels of education may also increase information needs (Kilicarslan-Toruner \& Akgun-Citak 2013) and thereby affect information-seeking behaviour.

Other factors that play a role in information seeking include socio-demographic characteristics and obesity (Snellman 2014); mother's age (e.g., Atuyambe, Mirembe, 
Tumwesigye, Annika, Kirumira \& Faxelid 2008); race and ethnicity (Rooks, Wiltshire, Elder, BeLue \& Gary 2012); spousal support (Guillory, Niederdeppe, Kim, Pollak, Graham, Olson \& Gay 2014); and attitudes, trust and willingness to pay for information (Nocell, Romano \& Stefani 2014).

Situational factors are also relevant (e.g. Mesters, van den Borne, De Boer \& Pruyn 2001). For example, information seeking can be affected by the personal relevance of the information being sought (Baldwin, Bruce \& Tiro 2013), the consumer's health literacy, relationship with their healthcare professional (Longo, Schubert, Wright, LeMaster, Williams \& Clore 2010), and pregnancy (e.g. Pandey, Hart \& Tiwary 2003, Lagan, Sinclair \& Kernohan 2010, Percheski \& Hargittai 2011).

The current study empirically examines the differences in information channel trust and how these are influenced by individual factors, and extends the research focus beyond current traditional communication model approaches. Previous models such as C-HIP have focused on individual cognitions, and assumed a staged sequence of decision-making following traditional decision-making models.

Thus, while service customers can choose from a broad array of information channels, from a theoretical and marketing perspective, understanding the relationship between use of and trust in information channels offers scope to increase the effectiveness of information provision and hence to change behaviour.

Overall, the research aim is to consider channel trust and its impact on channel use. , The problem requires examination from two perspectives: first, does a consumer (information seeker) most trust the information sources they use?; and, second, do they use what they most trust? We consider these research questions through the lens of motherhood and individual demographic factors as potential impacts on such trust. 


\section{Methodology}

This study involved collecting and analysing survey data on the use of and trust in information channels by pregnant women and mothers of young children.

Test instrument

An electronic invitation was emailed Australia-wide in the period 8-21 December 2009 to pregnant women and mothers with young children. The age of the data is acknowledged, and the potential impact on factors such as role and importance of Internet usage are established in the limitations section. Access to this type of sample, specifically Mothers and countrywide, comprised a unique opportunity to deeply explore the nature of trust and information channels.

The survey included two focused questions relating to information channels and trust. The first question specified five information channels: friends, family, health professionals, the Internet, and parenting magazines. Women were asked to allocate 100 points among the channels they most commonly used, with more points indicating higher usage. The second question asked women to rank their trust in all five channels (whether used or not), from 1 (most trusted) to 5 (least trusted).

In addition to the socio-demographic characteristics flagged in the literature, other potential explanatory factors were included. The presence of other adults in the house (such as a spouse, the respondent's parents or other adults) was considered to represent an alternative source of information. Household income and eligibility for family assistance, such as child benefits aimed at low-income single or two-parent families, captured economic circumstances (Australian Government Department of Families 2010). 
From a total of 9000 emails sent, 1500 email invitations were opened, and the full dataset comprised 640 surveys, representing an effective response rate of 42.6 per cent. After removing surveys with missing or invalid responses, the resulting sample contained 472 completed surveys.

\section{Modeling methodology}

For modeling purposes, the two extremes of trust form the focus. A multinomial logit model - based on a utility-maximizing framework - is specified for the choice of most (and least) trusted information channel, and a selection of other variables (such as demographic characteristics) are used as the regressors (associated or 'explanatory’ factors). ${ }^{1}$

Parameters in these non-linear probability models are not easily interpreted, so marginal effects are computed instead. Each marginal effect represents the (average) estimated change in the probability of a particular channel being rated as most (or least) trusted, given a marginal change in the associated regressor - much like in a typical regression model. Although the interpretation is similar to that for a linear regression, the underlying calculation differs, as the logit model is non-linear.

\section{Data analysis and modeling results}

After presenting some descriptive statistics, information use and trust, and the extent to which they align, are examined. The modeling results are reported, and the relationship between trust and the number of channels used by two groups of women in the sample is further explored.

\footnotetext{
${ }^{1}$ Since the data are cross-sectional, we cannot identify any estimated effects as being causal.
} 


\section{Descriptive statistics}

The most common characteristics of the women in the sample were as follows: aged between 30 and 34 years old (33 per cent), had a tertiary degree (26 per cent), other adults lived in the household (90 per cent, mostly spouse/de facto partner), annual household income of between $\$ 52,001$ and $\$ 104,000$ (48 per cent), eligible for family assistance (76 per cent) and further plans to extend the family (61 per cent).

Most respondents in the sample were mothers who were not currently pregnant and had at least one child aged less than two years (72 per cent). The most common number of children was one (44 per cent) and the most common age of the youngest child was less than one year (46 per cent).

\section{Information channel use and trust}

Most women (59 per cent) used all five information channels (to some extent) and another 24 per cent used any four of the five channels (see Table 1). Only 1.5 per cent of the women routinely restricted their information seeking to a single channel. With an average number of channels of 4.3, the prevalence of multiple channel use is consistent with the findings in the health information seeking literature (for example, 3.6 channels in Cotton \& Gupta 2004).

\section{Table 1: Number of information channels used}

\begin{tabular}{|l|c|c|c|c|c|}
\hline & \multicolumn{5}{|c|}{ Number of channels used (n) } \\
\cline { 2 - 6 } & $\mathbf{1}$ & $\mathbf{2}$ & $\mathbf{3}$ & $\mathbf{4}$ & $\mathbf{5}$ \\
\hline $\begin{array}{l}\text { Percentage of sample using } \\
n \text { channels (n=472) }\end{array}$ & 1.5 & 5.7 & 10.4 & 23.5 & 58.9 \\
\hline
\end{tabular}

In examining the extent to which mothers' use of information channels and trust in those channels align, there are two fundamental questions to answer. First, do the mothers most trust what they use? Second, do they use what they most trust? 
Table 2 summarises the relative intensity of use and the trust rankings for each channel. Family was the channel most likely to be used (91 per cent) and parenting magazines the least likely (79 per cent). Mothers allocated 100 points among each of the channels they used, with more points indicating higher usage. Analysis of those allocations indicates that family and health professionals tended to be used the most intensively: users of those channels allocated about 27 points to each channel on average (among non-users, the average allocation was 25 points for family and 23 points for health professionals). Magazines were used the least intensively, receiving 18 points on average by users.

The channel most likely to be ranked as the most trusted was health professionals (46 per cent), followed by family (34 per cent) and friends (11 per cent). The channels most likely to be ranked as the least trusted were the Internet ( 45 per cent) and magazines ( 24 per cent). There appears to be a relationship between use and trust, as the likelihood of a channel being the most trusted was higher among users of that channel than among the overall sample, and the likelihood of a channel being least trusted was lower among users of that channel than among the overall sample. Average trust rankings for each channel were also closer to one among users than for the overall sample.

In relation to using what is most trusted, most mothers used the channel they ranked as their most trusted (although the intensity of use varied somewhat by channel). For example, of the 46 per cent who ranked health professionals as the most trusted channel, about 95 per cent used that channel and allocated an average of about one-third of the 100 points to it. Conversely, all of the 3.4 per cent who most trusted the Internet also used it and allocated it an average of 57 points. However, if a mother most trusted the Internet, it was likely to be her main (or perhaps only) channel used; whereas if a mother most trusted health professionals, she also tended to use other channels. 
In terms of level of trust in the most used channel, about 80 per cent of mothers indicated a single channel as their most used (with the remaining 20 per cent indicating that between two and five channels were equally their most used). Among users (for each information channel), family was most likely to be the single most used channel (30 per cent), followed by health professionals (25 per cent). Among their users, the remaining channels were much less likely to be rated as the single most used information channel. Mothers who most used a single channel were highly likely to rank it as their most trusted channel if it was health professionals (87 per cent) or family (78 per cent), but much less likely to rank it as their most trusted if it was magazines (34 per cent) or the Internet (22 per cent).

Interestingly, about 86-8 per cent of mothers used friends and/or the Internet as an information channel and their average usage of each was the same (21 points). These mothers were marginally more likely to nominate the Internet as the single most used channel (16 per cent) than friends (12 per cent). However, those mothers who mostly used friends for information were more than twice as likely to rank their most used channel as their most trusted (46 per cent) relative to mothers who mostly used the Internet (22 per cent).

Table 2: Types of information channel - use and trust

\begin{tabular}{|c|c|c|c|c|c|}
\hline \multirow[b]{2}{*}{ Measures of use and/or trust } & \multicolumn{5}{|c|}{ Information channel } \\
\hline & Family & Friend & $\begin{array}{l}\text { Health } \\
\text { prof. }\end{array}$ & $\begin{array}{l}\text { Mag- } \\
\text { azine }\end{array}$ & Internet \\
\hline Percentage of sample using the channel & 90.89 & 88.77 & 87.71 & 79.03 & 86.23 \\
\hline Average usage by users (points /100) & 27.85 & 21.37 & 26.10 & 18.23 & 21.36 \\
\hline $\begin{array}{l}\text { Average usage } \\
{\text { (points } / 100)^{\mathbf{a}}}^{\mathbf{a}}\end{array}$ & 25.32 & 18.97 & 22.90 & 14.41 & 18.42 \\
\hline Average number of other channels used (/4) & 3.49 & 3.52 & 3.54 & 3.66 & 3.53 \\
\hline $\begin{array}{l}\text { Percentage of sample ranking the channel as } \\
\text { most trusted }\end{array}$ & 34.11 & 11.02 & 45.55 & 5.93 & 3.39 \\
\hline $\begin{array}{l}\text { Percentage of users ranking the channel as most } \\
\text { trusted }\end{array}$ & 36.13 & 12.41 & 49.03 & 7.24 & 3.93 \\
\hline $\begin{array}{l}\text { Percentage of sample ranking the channel as } \\
\text { least trusted }\end{array}$ & 9.32 & 19.07 & 2.97 & 23.73 & 44.92 \\
\hline $\begin{array}{l}\text { Percentage of users ranking the channel as least } \\
\text { trusted }\end{array}$ & 6.99 & 15.51 & 2.66 & 16.89 & 40.05 \\
\hline
\end{tabular}




\begin{tabular}{|l|l|l|l|l|l|}
\hline Average trust ranking in sampleb & 2.39 & 3.16 & 1.92 & 3.52 & 4.01 \\
\hline Average trust ranking by users & 2.27 & 3.06 & 1.86 & 3.34 & 3.90 \\
\hline $\begin{array}{l}\text { Percentage of 'most trusteds' who use the } \\
\text { channel }\end{array}$ & 96.27 & 100.00 & 94.42 & 96.43 & 100.00 \\
\hline $\begin{array}{l}\text { Average use by users who most trusted the } \\
\text { channel }\end{array}$ & 42.57 & 37.98 & 33.92 & 39.26 & 57.19 \\
\hline $\begin{array}{l}\text { Percentage of users nominating the (single) } \\
\text { channel as most used c }\end{array}$ & 29.60 & 12.41 & 25.36 & 9.38 & 15.72 \\
\hline $\begin{array}{l}\text { Percentage of 'most used' who ranked the } \\
\text { channel as most trustedd }\end{array}$ & 77.95 & 46.15 & 86.67 & 34.29 & 21.88 \\
\hline
\end{tabular}

$\mathbf{a}$ Non-users allocate zero points to the channel. ${ }^{\mathbf{b}}$ Trust rankings were measured on a scale from 1 (most trusted) to 5 (least trusted).

c Analysis of usage scores revealed that about 80 per cent of the sample had a single channel they used most. The other 20 per cent used two or more channels equally. $\mathbf{d}$ 'Most used' refers to individuals whose usage scores showed that channel to be the single most used.

\section{Modeling results}

Mothers ranked the information channels, from most to least trusted. A multinomial logit model was used to estimate how a selection of variables was associated with the probability of each channel being chosen as the most (or least) trusted. This type of model controls for confounding influences on the relationships (Graddy 1998). The Internet was chosen as a base outcome in the regression analysis, although this did not affect the results.

The explanatory variables were as follows. Degree is a dummy variable for highest education level and takes a value of 1 when the respondent has a tertiary degree or higher, and 0 for lower education levels. Number of channels indicates how many information channels were used (from 1 to 5). Age was included using a dummy variable for each category, with 30-34 years used as the reference category. Income also used a set of dummy variables, with 'up to $\$ 52,000$ ' mean total income used as the reference. Others in household was a dummy variable indicating whether there were other adults (such as a partner, parent or other adult) living with the respondent. Number of children ranged from 0 to 11 and was included as a continuous variable.

Other variables were tested, including age of the youngest child, eligibility for family assistance and plans to extend the family. However, none of these variables had a significant 
effect so they were dropped from the model (these results are available upon request from the authors).

The results presented in Table 3 show the marginal effect of a change in the associated variable on the probability of the information channel being ranked as the most trusted, with other variables held constant. As the marginal effects measure the percentage change in a probability, a large marginal effect can indicate a small absolute change if the probability of that channel being ranked as, say, the most trusted channel is low to begin with.

Having a tertiary degree or higher qualification is associated with a 12.1 per cent increase in the probability of ranking health professionals as the most trusted information channel, at the expense of a 12.3 per cent decrease in the probability of ranking family as the most trusted information channel. The other channels are not significantly affected by education level. The number of channels used has a small but significant effect on trust in health professionals each additional information channel used increases the probability that health professionals are the most trusted channel by 5 per cent. Yet trust in other information channels is not significantly affected by the number of channels used.

Marginal effects for age are interpreted relative to being aged 30-34 years. Therefore, relative to someone aged 30-34, being under 25 years old is associated with a 21.3 per cent increase in the probability of ranking family as the most trusted channel and a 6.6 per cent increase in the likelihood of Internet being ranked the most trusted channel. This youngest age group is also less likely than the 30-34 year olds to rank health professionals and magazines as the most trusted channel. Being in the oldest group (aged 40 or over) is associated with a lower probability of ranking friends (8.5 per cent) or the Internet (3.5 per cent) as the most trusted channel (relative to the rankings by 30-34 year olds, all else being equal). 
The (relative) effects of income on trust are only significant when (gross annual) income exceeds $\$ 156,000$. For example, relative to those with an income of up to $\$ 52,000$, women with an income of between $\$ 156,001$ and $\$ 208,000$ are 21.5 per cent less likely to rank health professionals (and 3.6 per cent less likely to rank the Internet) as the most trusted information channel(s). Women with an income of over $\$ 208,000$ are 20.1 per cent less likely to rank family as their most trusted channel, and 4.6 per cent less likely to rank magazines as their most trusted channel.

Having other adults in the household significantly lowers trust in health professionals (23 per cent), family (11.7 per cent) and friends (11.4 per cent), all else being equal. However, the probability of ranking the Internet as the most trusted channel increases by 49.8 per cent if there are others in the household. The number of children has no significant effect on the rankings of the most trusted information channel.

Table 3: Multinomial logit model for the channel rated as most trusted ${ }^{a}$

\begin{tabular}{|c|c|c|c|c|c|}
\hline \multirow[b]{2}{*}{ Variable } & \multicolumn{5}{|c|}{ Information channel rated as most trusted } \\
\hline & Family & Friend & $\begin{array}{c}\text { Health } \\
\text { professional }\end{array}$ & Magazine & Internet \\
\hline \multirow[t]{2}{*}{ Degree } & $-0.123^{* * *}$ & -0.021 & $0.121^{* *}$ & 0.022 & 0.002 \\
\hline & $(0.047)$ & $(0.033)$ & $(0.050)$ & $(0.022)$ & $(0.018)$ \\
\hline \multirow[t]{2}{*}{ Number of channels } & -0.024 & -0.006 & $0.051 * *$ & -0.008 & $-0.013 *$ \\
\hline & $(0.022)$ & $(0.014)$ & $(0.023)$ & $(0.013)$ & $(0.008)$ \\
\hline \multicolumn{6}{|l|}{ Age (base: 30-34) } \\
\hline \multirow[t]{2}{*}{ Under 25} & $0.213^{* * *}$ & -0.041 & $-0.160 * *$ & $-0.078 * *$ & $0.066 *$ \\
\hline & $(0.078)$ & $(0.046)$ & $(0.076)$ & $(0.035)$ & $(0.040)$ \\
\hline \multirow[t]{2}{*}{$25-29$} & 0.075 & -0.036 & -0.008 & -0.022 & -0.009 \\
\hline & $(0.057)$ & $(0.038)$ & $(0.061)$ & $(0.029)$ & $(0.021)$ \\
\hline \multirow[t]{2}{*}{$35-39$} & 0.012 & 0.052 & -0.043 & -0.010 & -0.011 \\
\hline & $(0.056)$ & $(0.045)$ & $(0.063)$ & $(0.034)$ & $(0.021)$ \\
\hline \multirow[t]{2}{*}{40 or over } & 0.137 & $-0.085^{* *}$ & 0.014 & -0.031 & $-0.035^{* * *}$ \\
\hline & $(0.092)$ & $(0.044)$ & $(0.098)$ & $(0.053)$ & $(0.014)$ \\
\hline \multicolumn{6}{|c|}{ Income (base: up to $\$ 52,000$ ) } \\
\hline \multirow[t]{2}{*}{$\$ 52,001-104,000$} & 0.006 & 0.020 & -0.035 & 0.010 & 0.000 \\
\hline & $(0.053)$ & $(0.036)$ & $(0.056)$ & $(0.024)$ & $(0.019)$ \\
\hline$\$ 104,001-156,000$ & 0.010 & 0.000 & -0.031 & 0.039 & -0.018 \\
\hline
\end{tabular}




\begin{tabular}{|l|l|l|l|l|l|}
\hline & $(0.078)$ & $(0.050)$ & $(0.082)$ & $(0.042)$ & $(0.025)$ \\
\hline \multirow{3}{*}{ \$156,001-208,000 } & 0.106 & 0.087 & $-0.215^{*}$ & 0.058 & $-0.036^{* * *}$ \\
\cline { 2 - 6 } & $(0.117)$ & $(0.093)$ & $(0.110)$ & $0.066)$ & $(0.013)$ \\
\hline \multirow{3}{*}{ Over \$208,000 } & $-0.201^{*}$ & 0.038 & 0.102 & $-0.046^{*}$ & 0.107 \\
\cline { 2 - 6 } & $(0.105)$ & $(0.119)$ & $(0.159)$ & $(0.026)$ & $(0.105)$ \\
\hline Numbers in household & $-0.117^{*}$ & $-0.114^{* * *}$ & $-0.230^{* *}$ & -0.037 & $0.498^{* * *}$ \\
\cline { 2 - 6 } & $(0.062)$ & $(0.041)$ & $(0.099)$ & $(0.044)$ & $(0.073)$ \\
\cline { 2 - 6 } & 0.025 & 0.000 & -0.016 & -0.011 & 0.002 \\
\cline { 2 - 6 } & $(0.017)$ & $(0.010)$ & $(0.018)$ & $(0.011)$ & $(0.005)$ \\
\hline
\end{tabular}

a Marginal effects, with standard errors in parentheses. Likelihood ratio test $\left(\chi^{2}(48)\right)=69.58(\mathrm{p}=0.025)$. Pseudo $\mathrm{R}^{2} 0.0594$. Sample size $\mathrm{n}=467 .{ }^{* * *} \mathrm{p}<0.01,{ }^{* *} \mathrm{p}<0.05, * \mathrm{p}<0.10$.

The results for the least trusted information channel did not always align with those for the most trusted channel. Some factors that significantly reduce the probability of a channel being ranked as most trusted were not sufficiently large to significantly affect the probability of that same channel being ranked as the least trusted (see Table 4). For example, while having a degree or higher qualification significantly reduces the probability of family being the most trusted channel and significantly increases the probability of family being ranked as least trusted, the effect of higher education in significantly increasing trust in health professionals does not manifest in any significant reduction in the probability of health professionals being ranked as the least trusted channel. That is, most of the explanatory variables are likely to change the ordering of most to least trusted channel, but not sufficiently to make the most trusted channel the least likely to become the least trusted (or vice versa).

Higher levels of education are associated with an 8.9 per cent lower probability of the Internet being ranked as the least trusted channel, but a 14.8 per cent higher probability of family being least trusted. For each additional information channel used, the probability of magazines being the least trusted channel declines by 3.5 per cent. The only significant effects of age are for 25-29 year olds relative to 30-34 year olds, revealing a 7.5 per cent 
lower probability for family and a 4.4 per cent higher probability for health professionals being the least trusted information channel.

As household income increases, family becomes more trusted (the probability of family being least trusted declines significantly at the higher income levels). Friends are less likely to be the least trusted channel for women with a household income of between \$156,001 and 208,000 (relative to women in the lowest income bracket of up to $\$ 52,000$ ). Health professionals become more likely to be the least trusted channel for women with an income of \$52,001-104,000 and \$156,001-208,000 relative to those in households with an income of up to $\$ 52,000$. Magazines increase in trust for mothers with an income of over $\$ 208,000$ but are more likely to be the least trusted channel for those with a moderate income in the \$104,001-156,000 range. Higher incomes are associated with more trust in the Internet, particularly when incomes range between $\$ 104,001$ and $\$ 156,000$.

The presence of other adults in the household serves to increase trust in family and health professionals by reducing the probability of either of these two channels being rated as the least trusted. Only the number of children has a significant effect on trust in magazines, as each additional child increases the probability of magazines being the least trusted channel by 3 per cent.

Table 4: Multinomial logit model for the channel rated as least trusteda

\begin{tabular}{|c|c|c|c|c|c|}
\hline \multirow[b]{2}{*}{ Variable } & \multicolumn{5}{|c|}{ Information channel rated as least trusted } \\
\hline & Family & Friend & $\begin{array}{l}\text { Health } \\
\text { professional }\end{array}$ & Magazine & Internet \\
\hline \multirow[b]{2}{*}{ Degree } & $0.148^{* * *}$ & -0.014 & -0.009 & -0.036 & $-0.089 *$ \\
\hline & $(0.033)$ & $(0.040)$ & $(0.015)$ & $(0.043)$ & $(0.050)$ \\
\hline \multirow[b]{2}{*}{ Number of channels } & -0.009 & 0.004 & 0.008 & $-0.035 *$ & 0.032 \\
\hline & $(0.014)$ & $(0.018)$ & $(0.009)$ & $(0.018)$ & $(0.024)$ \\
\hline \multicolumn{6}{|l|}{ Age (base: 30-34) } \\
\hline \multirow[b]{2}{*}{ Under 25} & -0.042 & -0.020 & 0.016 & 0.011 & 0.036 \\
\hline & $(0.044)$ & $(0.057)$ & $(0.030)$ & $(0.072)$ & $(0.082)$ \\
\hline $25-29$ & $-0.075 * *$ & 0.010 & $0.044^{* *}$ & 0.056 & -0.035 \\
\hline
\end{tabular}




\begin{tabular}{|c|c|c|c|c|c|}
\hline & $(0.033)$ & $(0.049)$ & $(0.022)$ & $(0.053)$ & $(0.061)$ \\
\hline \multirow[b]{2}{*}{ 35-39 } & -0.009 & -0.007 & 0.024 & 0.022 & -0.029 \\
\hline & $(0.038)$ & $(0.051)$ & $(0.018)$ & $(0.053)$ & $(0.062)$ \\
\hline \multirow[b]{2}{*}{40 or over } & -0.080 & -0.046 & 0.017 & -0.026 & 0.135 \\
\hline & $(0.054)$ & $(0.078)$ & $(0.029)$ & $(0.077)$ & $(0.101)$ \\
\hline \multicolumn{6}{|c|}{ Income (base: up to $\$ 52,000$ ) } \\
\hline \multirow[b]{2}{*}{$\$ 52,001-104,000$} & -0.021 & -0.068 & $0.045^{* *}$ & 0.051 & -0.007 \\
\hline & $(0.039)$ & $(0.044)$ & $(0.019)$ & $(0.047)$ & $(0.054)$ \\
\hline \multirow[b]{2}{*}{$\$ 104,001-156,000$} & $-0.073^{*}$ & -0.019 & 0.058 & $0.176 * *$ & $-0.141^{*}$ \\
\hline & $(0.042)$ & $(0.065)$ & $(0.040)$ & $(0.079)$ & $(0.077)$ \\
\hline \multirow[b]{2}{*}{$\$ 156,001-208,000$} & $-0.095^{* *}$ & $-0.143^{* *}$ & $0.169 *$ & 0.095 & -0.026 \\
\hline & $(0.043)$ & $(0.065)$ & $(0.093)$ & $(0.103)$ & $(0.114)$ \\
\hline \multirow[b]{2}{*}{ Over 208,000 } & $-0.124 * * *$ & 0.286 & -0.007 & $-0.186 * * *$ & 0.032 \\
\hline & $(0.032)$ & $(0.193)$ & $(0.004)$ & $(0.034)$ & $(0.194)$ \\
\hline \multirow[b]{2}{*}{ Others in household } & $-0.083^{*}$ & 0.063 & $-0.072^{* * *}$ & 0.002 & 0.090 \\
\hline & $(0.045)$ & $(0.068)$ & $(0.025)$ & $(0.074)$ & $(0.085)$ \\
\hline \multirow[b]{2}{*}{ Number of children } & -0.005 & -0.003 & 0.005 & $0.030 * *$ & -0.026 \\
\hline & $(0.009)$ & $(0.015)$ & $(0.005)$ & $(0.014)$ & $(0.020)$ \\
\hline
\end{tabular}

a Marginal effects, with standard errors in parentheses. Likelihood ratio test $\left(\chi^{2}(48)\right)=84.80(p=0.000)$. Pseudo $\mathrm{R}^{2} 0.0676$. Sample size $\mathrm{n}=467 . * * * \mathrm{p}<0.01, * * \mathrm{p}<0.05, * \mathrm{p}<0.10$

\section{Selected effects in more detail}

The modeling of Australian mothers' trust in information channels relating to healthcare for their young children shows that having a tertiary degree or higher qualification is associated with more trust in health professionals and, to a lesser extent, the Internet relative to the other channels, but is also associated with relatively less trust in information obtained from family. An increase in the number of channels used is also associated with more trust in health professionals and magazines but less trust in the Internet. Other variables also show interesting effects on trust.

This paper now graphically explores the relationship between trust and a selection of other variables for two groups of mothers in the sample with particular characteristics. Rather than compare theoretical or one-off combinations of characteristics according to particular values of the explanatory variables used in the modeling, the mothers are grouped according to their 
observed combinations of those characteristics, and the two largest groups are selected for comparison. The first group comprised 22 mothers with a degree or higher qualification, aged 30 -34, with a household income of $\$ 52,001-104,000$, who had one child and other adults living in the household. The second group comprised 21 mothers without a degree or higher qualification, aged 25-29, but who otherwise shared the same characteristics as the first group. Thus, put simply, Group 1 included older, more educated mothers than Group 2. For each group, the model is used to predict the probability of each channel being most (or least) trusted. Comparing these two groups, therefore, enables exploration of some of the effects on trust caused by variations in age and education according to the number of channels used.

For each group of mothers, Figure 1 shows the predicted probability of each channel being ranked as the most trusted, according to increasing numbers of channels used. For both groups, trust in the Internet and magazines declined marginally as the number of channels used increased. The older, more educated mothers (Group 1) were most likely to trust health professionals over family and, as the number of channels used increased, this gap in their trust also increased. For the younger, less educated mothers, the most trusted channel was family if only one channel was used. However, as these women increased the number of information channels used, the probabilities of them ranking family or health professionals as the most trusted converged until, at five channels, the probability of placing the most trust in health professionals exceeded that for family.

In Group 1, both education and age are associated with a very large reduction in the probability of family being the most trusted channel and a small increase in the probability of magazines being most trusted. Education alone accounts for the increase in trust in health professionals, while the small increase in trust in the Internet comes from age. The 
probability of friends being the most trusted channel is essentially unchanged as the combination of education and age effects offset each other.

Figure 1: Probability of each channel being the most trusted for the two groups of women

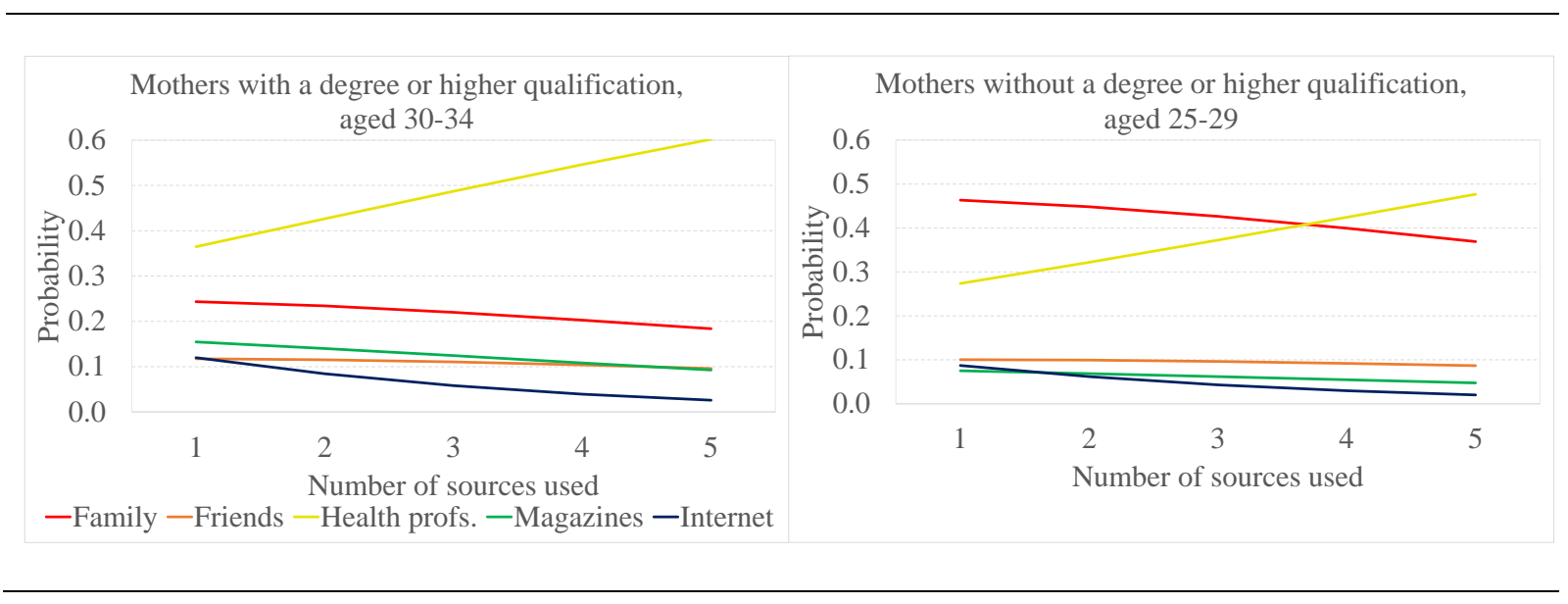

Figure 2 shows the predicted probability of each channel being ranked the least trusted by the two groups of mothers. The least trusted information channel was most likely to be family, followed by the Internet, among older, more educated mothers who used only one or two information channels. However, if this group used three or more information channels, the Internet became the most likely channel to be rated as the least trusted. Moreover, as these women increased the number of channels used, the probability of the Internet being rated as least trusted steadily increased.

For the younger, less educated mothers in Group 2, magazines had the highest probability of being ranked as the least trusted channel (marginally ahead of the Internet) if only one information channel was used. However, using more than one channel was associated with the Internet being the most likely channel to be the least trusted. This 'distrust' effect intensified as these women increased the number of information channels used. 
Interestingly, for both groups, friends tend not to be either the most or least trusted information channel. Rather, friends tend to be rated somewhere in the middle of the trust rankings, irrespective of the number of channels used.

The effects of age and education on trust in family and magazines are consistent with those shown in Figure 1 - higher education and older age both reduce trust in these two channels, in this case increasing the probability of being the least trusted channel. However, the (very small) increase in trust (lower probability of being least trusted) in health professionals here is mostly the result of age rather than education. The increase in trust in the Internet is due to education (but is partly offset by age). Trust in friends is marginally higher as a result of both education and age.

\section{Figure 2: Probability of each channel being the least trusted for the two groups of}

\section{women}

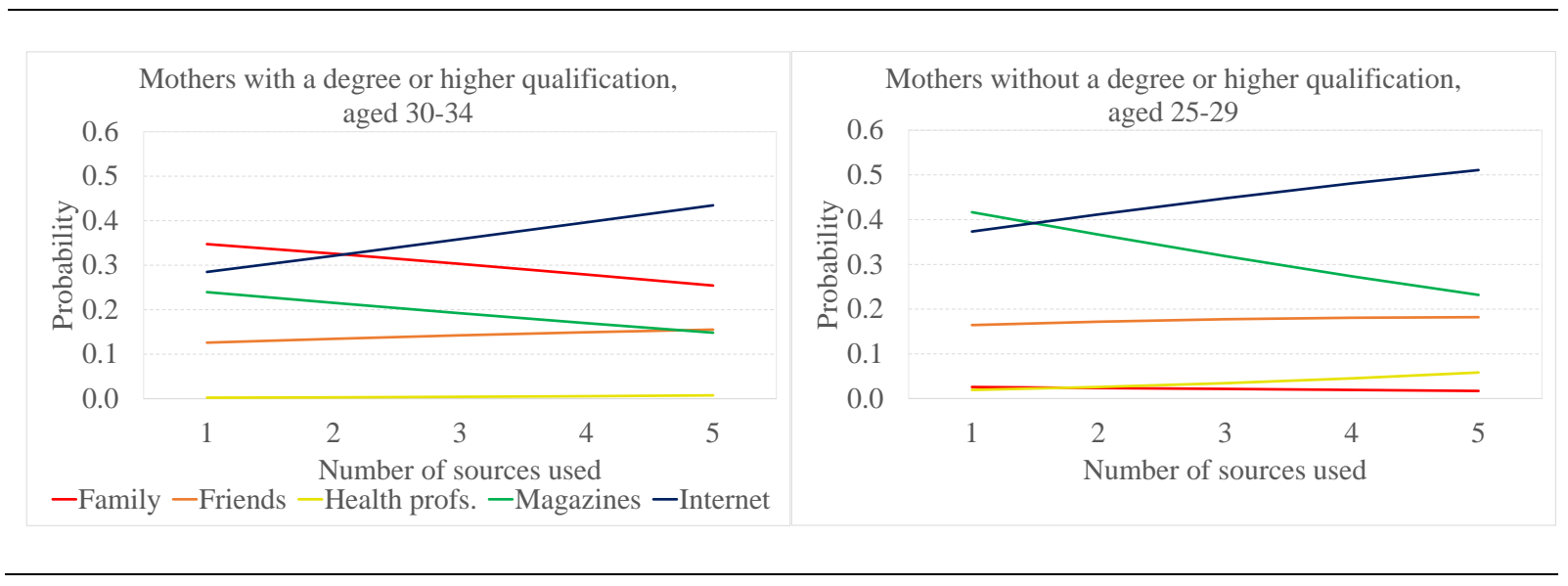

The differences in the effects of age and education between Figures 1 and 2 occur because the charts represent effects on the same concept (trust) but measured at different ends of the spectrum. As a result, for example, trust in the Internet is driven at the upper extreme (most trusted channel) by age through a small effect, but is driven at the lower extreme (least trusted channel) mostly by education through a large effect. In essence, underlying trust in the Internet is very low relative to the other channels, and although the ranking increases with 
education level (and age), the increase is only sufficient to move the ranking from the lower extreme to the middle. Almost the exact opposite explanation applies to health professionals, for whom the underlying level of trust is very high.

\section{Discussion}

The current study contributes to the services marketing literature in two main ways. First, in empirically examining information channel trust, it provides insights that can enhance the predictive capability of communication theory. In the past, models such as C-HIP have focused on individual cognitions, based on a staged sequence of decision-making in line with traditional decision-making models, and have thereby ignored channel attributes such as channel trust.

The lack of consideration of channel trust in the literature is particularly problematic in light of the common practice of consumers using multiple channels simultaneously (Rangaswamy \& Van Bruggen 2005). The use of simultaneous channels is only the first step towards creating a customer-centric multichannel system (McGoldrick \& Collins 2007), but simply offering greater choices to assist decision-making during the information search stage of consumer behaviour is not the answer.

A key result to emerge from this research is that, while the informants' most trusted information channel was healthcare professionals, this was not the most common information channel used. In fact, mothers in this study exhibited many of the traits of 'the researchshopper' (Verhoef, Neslin \& Vroomen 2007, p. 129). Empowered users have compelled the healthcare profession to rethink the provision of services, including information, as patients increasingly come to appointments with information in hand, request specific treatments or procedures, and ask questions about the advice provided (Harris 2003). 
This increased accountability in the healthcare industry, coupled with the consumer's desire to make the 'right' decision (given the importance of the end-user - a mother's child), has given rise to a potentially more thoughtful, even rigorous, information search. The mothers in our study looked to multiple sources of information, rather than only the traditionally trusted option - the healthcare professional. However, these searches were not necessarily longer or more time consuming, in that seeking word of mouth referrals to complement the information provided by a healthcare professional can be relatively quick.

This study extends previous research, which found that trust lies at the center of information selection, including choice of information channel. For example, previous research has shown that, while health professionals remain the main source of choice for health information, there are significant variations in use and trust based on ethnicity and age (Smith 2011). This study expands on such research and considers the number of information sources and the role of trust in relation to each channel - for example, by identifying the important role that friends play regardless of the number of channels used. Further, the results presented here differ from those of prior research that considered the value mothers place on information channels and found that referrals from trusted channels (excluding healthcare professionals) were most important (Dobele \& Lindgreen 2011).

In addition, this research extends consideration of the individual beyond individual processing of information to explore whether the heterogeneity present in any services market warrants research attention within communication frameworks such as C-HIP. Specifically, this study examined whether individual demographic factors impact channel trust. The results highlight that the more educated a mother is, the more likely she will be to trust health professionals over other information channels, irrespective of the overall number of information channels used. Less educated mothers are more likely to trust family over 
other channels, unless they use all five information channels, in which case they are most likely to trust health professionals. In this regard, the impact of education is consistent with the findings of previous research that identified the importance of parental educational attainment in determining service outcomes (Hesse et al. 2005, Kostagiolas et al. 2013, Snellman 2014). Prior research also suggests that younger patients rely less on professional opinions (e.g., Graydon, Galloway, Palmer-Wickham, Harrison \& Bij 1997, Fox 2011), which is consistent with the present study's finding that (relative to older mothers) younger mothers tend to place less trust in health professionals.

\section{Limitations and Conclusions}

Overall, the aim of the current study was to explore whether communication models could benefit from the inclusion of channel trust and certain additional individual factors (such as demographics) to extend understanding beyond individual cognitions. A review of the literature revealed limited focus on information channels and channel trust, suggesting a considerable opportunity for future research on this within services marketing.

Future research could also consider iInternet usage, as the role of this communication medium and the time consumers spend engaging with the Internet are both constantly changing. Research might benefit from incorporating the actual use of the variety of sources and currency of the information presented, which is especially important given the role of the iInternet in providing medical information.

In addition, the Internet channel could be broken down to differentiate between online and traditional referrals and online and traditional media channels, such as healthcare professional blogs, online magazines and professional marketing messages from those outside the medical profession but who are connected to the health industry (for example, dieticians, child 
counsellors and school support, Government health departments and sporting and exercise bodies).

The current study did not apply the full C-HIP Model. It is suggested that future studies seek to understand the explanatory and predictive role of channel trust and individual factors (such as education) in influencing consumer information processing and subsequent purchasing behaviour. A longitudinal research design is also recommended given that C-HIP is a framework for structuring the stages involved in the flow of information from a channel to a receiver (Conzola \& Wogalter 2001). In addition to the inclusion of the variables used in the current study, additional factors warrant consideration in future studies. For example, factors identified in the literature review that were not included in the present study, such as health literacy and relationship with the healthcare professional (Longo et al. 2010), could be empirically examined.

The results of the current study highlight additional areas requiring further research attention. More than half of the respondents reported using all five information channels tested, suggesting that information is drawn from a diverse range of channels including friends and family, the service provider (healthcare professional) and mass media (such as magazines and the Internet). Communication theory and communication models such as C-HIP are framed according to a sender-receiver channel, which may oversimplify the reality. In practice, multiple channels are employed by senders, including service employees, so the complex interplay between channels (which includes service employees) could be considered in future studies.

Additional factors that might impact on health-related information-seeking behaviours and trust in information channels could be explored, such as psychological factors (including states and traits) (e.g. Case, Andrews, Johnson \& Allard 2005). At a deeper level, the 
decisions made by mothers form part of a staged process that includes a search for information and the evaluation of potential treatment options. What happens during these two stages is affected by all of the following: the importance or severity of the 'problem' (the health condition); contextual (in this case, health) literacy (which will, in turn, be affected by education level, exposure to information and prior experience); limits on the receiver's time, channel access and mental capacity to process information; effective access to information through various channels (such as friends or family, the Internet, books or magazines); channel-specific literacy (for example, the ability to effectively search the Internet); use of multiple channels versus a single channel; and trust in information channels.Such factors could be included into a mixed methods study.

Future research might also consider the importance of trust overall, as well as trust in individual channels. For example, researchers could compare search strategies when trust in a particular channel overall is low, yet trust in a particular source within that channel is high. For example, a consumer may distrust the Internet as a source of information but rely on one particularly trusted website. In such situations where the overall information channel is untrusted but single sources are, is the information seeker using this one source as a timesaving device, are limited in available sources or seeking to reduce the number of options. It would also be valuable to investigate such situations where consumers are using channels in which they have little trust. Thus, questioning why such channels are being used - is there a lack of choice, lack of access, historically favourable use of this particular source, or is it simply the case that these channels are always considered as a start (or end) point?

In addition to identifying the types of information sought from each channel, further research could seek to determine any correlation between the 'seriousness' of the issue being researched and the consumer's previous related experience (thus, linking to past research that 
considers the importance of the topic of interest (e.g. Gaglio et al. 2012)) with previous service experiences. Further, the nature of relationships with others in the household could be more fully explored - for example, by considering differences between relationships with biological relatives and a spouse or other household residents (extending the work of Guilloy et al. (2014)). Such research could also investigate the specific role of household members as sounding boards, decision influencers or benchmarks, and which family members' opinions are more highly valued (trusted) and why. As part of this type of study, future research could also consider the number of children as a proxy for parental experience and compare the use of and trust in information sources between experienced and less experienced parents. This research might also consider plans to extend the family as a reflection of future information needs and the influence on trust and source types over time (for example, changes in information channel use and trust for each child and changes from experiences during these child-rearing years).

Research into the social context of health information seeking and access could distinguish between the advice given by doctors and information received from support personnel in the healthcare industry, such as midwives, or from administrative personnel, such as receptionists at medical clinics. It would also be valuable to explore health information literacy in future research, as there is a greater need for such literacy (Kostagiolas et al. 2013) among users seeking to comprehend (Thiede 2005) the growing amount of information available via the Internet on an increasingly wide variety of topics.

Several caveats surrounding this analysis are noted here. This study was narrowly focused on the trust in and use of five health information channels by pregnant women and mothers. Future research could include fathers and fathers-to-be, additional information channels (such as defining multiple Internet or online channels), other healthcare settings, and other services. 
The data were collected via an Internet survey, which may have biased the results on the use of and trust in the Internet; thus, future research should consider using different study recruitment methods to avoid such biases. The data were collected over five years ago and the use of, and types of Internet sources may have varied since this time. In this study, the information channels were kept intentionally broad in order to develop an overall picture of channel trust to determine whether the construct warranted future research attention. It is therefore recommended that future research seek to first understand which information channels consumers report using, prior to assessing information channel trust and channel use. By focusing attention on the channels that consumers use more, greater certainty in findings can be obtained given that false positives will not exist in reporting, which may have occurred in the present study where consumers had to respond to five channels provided in the online survey. 


\section{References}

Alba, J. W. and J. W. Hutchinson (1987). "Dimensions of consumer expertise." Journal of Consumer Research 13: 411-454.

Álvarez, B. and M. Vera-Hernández (2013). "Exploiting subjective information to understand impoverished children's use of health care." Journal of Health Economics 32(6): 1194-1204.

Arora, N. K., B. W. Hesse and B. K. Rimer (2008). "Frustrated and confused: the American public rates its cancer related information-seeking experiences." J Gen Intern Med 23(3): 223-228.

Atuyambe, L., F. Mirembe, N. M. Tumwesigye, J. Annika, E. K. Kirumira and E. Faxelid (2008). "Adolescent and adult first time mothers' health seeking practices during pregnancy and early motherhood in Wakiso district, central Uganda." Reproductive Health 5(1): 13.

Australian Government Department of Families, H. C. S. a. I. A. F. (2010). Income Support Customers: a Statistical Overview, 2009. FaHCSIA. Canberra, Australia.

Baldwin, A. S., C. M. Bruce and J. A. Tiro (2013). "Understanding how mothers of adolescent girls obtain information about the human papillomavirus vaccine: Associations between mothers' health beliefs, information seeking, and vaccination intentions in an ethnically diverse sample." Journal of Health Psychology 18(7): 926-938.

Bennett, R. and S. R. Rundle-Thiele (2004). "Customer satisfaction should not be the only goal." Journal of Services Marketing 18(7): 514-523.

Berry, L. L. and N. Bendapudi (2007). "Health Care: A Fertile Field for Service Research." Journal of Service Research 10(2): 111-122.

Bikhchandani, S. D., D. Hirshleifer and I. Welch (1991). "A theory of fads, fashions, custom and cultural change as information cascades." Journal of Political Economy 100: 992-1026.

Bloom, G., H. Standing and R. Lloyd (2008). "Markets, information asymmetry and health care: towards new social contracts." Social science \& medicine 66: 2076-2087.

Case, D. O., J. E. Andrews, J. D. Johnson and S. L. Allard (2005). "Avoiding versus seeking: the relationship of information seeking to avoidance, blunting, coping, dissonance, and related concepts." Journal of the Medical Library Association 93(3): 353.

Cheng, X., S. Fu and G.-J. de Vreede (2017). "Understanding trust influencing factors in social media communication: A qualitative study." International Journal of Information Management 37(2): 25-35.

Chesney, T., S. H. Chuah, A. Dobele and R. Hoffman (2017). "Information richness and trust in v-commerce: implications for services marketing." Journal of Services Marketing 31(3). 
Conzola, V. C. and M. S. Wogalter (2001). "A communication-human information processing (C-HIP) approach to warning effectiveness in the workplace." Journal of Risk Research 4(4): 309-322.

Cotton, S. R. and S. S. Gupta (2004). "Characteristics of online and offline health information seekers and factors that discriminate between them." Social Science \& Medicine 59: 17951806.

Criéa, D. and J.-C. Chebatb (2013). "Health marketing: Toward an integrative perspective." Journal of Business Research 66(1): 123-126.

Della, L. J., D. Eroglu, J. M. Bernhardt, E. Edgerton and J. Nall (2008). "Looking to the future of new media in health marketing: deriving propositions based on traditional theories." Health Marketing Quarterly 24(1-2): 147-174.

Deshpande, R. (1983). "'Paradigms Lost": On Theory and Method in Research in Marketing." Journal of Maketing 47(Fall): 101-110.

Dobele, A. and A. Lindgreen (2011). "Exploring the nature of value in the word-of-mouth referral equation for health care." Journal of Marketing Management 27(3-4): 269-290.

Dorsey, R. and T. Songer (2006). "Lifestyle behaviors and physician advice for change among overweight and obese adults with prediabetes and diabetes in the United States." Prev Chronic Dis 8: A132.

Dwyer, D. S. and H. Liu (2013). "The Impact of Consumer Health Information on the Demand for Health Services." The Quarterly Review of Economics and Finance 53: 1-11.

Elnaga, A. A. and S. S. Abunayyan (2016). "Determinants and Consequences of Advertising on Consumer Trust and Buying Behavior." Journal of American Science 12(4).

Fisher, C. M. and C. J. Anderson (1990). "Hospital Advertising: Does it Influence Consumers?" Journal of Health Care Marketing 10(4): 40-46.

Fox, S. (2011). The social life of health information. P. R. C. Pew Internet and American Life Project, California HealthCare Foundation. California: 1-45.

Gaglio, B., R. E. Glasgow and S. S. Bull (2012). "Do patient preferences for health information vary by health literacy or numeracy? A qualitative assessment." Journal of health communication 17(sup3): 109-121.

Gombeski, J. W. R., P. A. Carroll and J. A. Lester (1990). "Minicase: Influencing DecisionMaking of Referring Physicians." Journal of Health Care Marketing 10(4): 56-60.

Grabner-Kräuter, S. and S. Bitter (2013). "Trust in online social networks: A multifaceted perspective." Forum for Social Economics 44(1): 48-68. 
Graddy, E. A. (1998). Multivariate Regression Analysis in Public Policy and Administration. In Handbook of Research Methods in Public Administration. G. Miller and M. L. Whicker. Marcel Dekker, New York: 377-408.

Gray, N. J., J. D. Klein, P. R. Noyce, T. S. Sesselberg and J. A. Cantrill (2005). "Health information-seeking behaviour in adolescence: the place of the Internet." Social Science \& Medicine 60: 1467-1478.

Graydon, J., S. Galloway, S. Palmer-Wickham, D. Harrison and L. R. Bij (1997).

"Information needs of women during early treatment for breast cancer." Journal of Advanced Nursing 26(1): 59-64.

Greer, D., R. Russell-Bennett, A. Tombs and J. Drennan (2014). "Just what the doctor ordered? Investigating the impact of health service quality on consumer misbehaviour." Australasian Marketing Journal 22(3): 257-267.

Guillory, J., J. Niederdeppe, H. Kim, J. P. Pollak, M. Graham, C. Olson and G. Gay (2014). "Does Social Support Predict Pregnant Mothers' Information Seeking Behaviors on an Educational Website?" Maternal Child Health.

Ha, S. and Y. J. Lee (2011). "Determinants of consumer-driven healthcare: Self-confidence in information search, health literacy, and trust in information sources." International journal of pharmaceutical and healthcare marketing 5(1): 8-24.

Ham, C. and K. Alberti (2002). "The medical profession, the public and the government." British Medical Journal 324: 838-842.

Harris, K. M. (2003). "How Do Patients Choose Physicians? Evidence from a National Survey of Enrollees in Employment-Related Health Plans." Health Services Research 38(2): 711-732.

Hesse, B. W., D. E. Nelson, G. L. Kreps, R. T. Croyle, N. K. Arora, B. K. Rimer and K. Viswanath (2005). "Trust and sources of health information - the impact of the Internet and its implications for health care providers: findings from the first health information national trends survey." Archives of Internal Medicine 165(December): 2618-2624.

Holman, H. and K. Lorig (2000). "Patients as partners in managing chronic disease. Partnership is a prerequisite for effective and efficient health care." British Medical Journal 320(7234): 526-527.

Hupcey, J. E., J. Penrod, J. Morse and C. Mitcham (2001). "An exploration and advancement of the concept of trust." Journal ofAdvanced Nursing 36(2): 282-293.

Jensen, J. D., M. Liu, N. Carcioppolo, K. K. John, M. Krakow and Y. Sun (2016). "Health information seeking and scanning among US adults aged 50-75 years: Testing a key postulate of the information overload model." Health informatics journal: 1460458215627290. 
Karrh, J. (2002). "Managing word-of-mouth." Arkansas Business 1.

Kilicarslan-Toruner, E. and E. Akgun-Citak (2013). "Information seeking behaviours and decision-making process of parents of children with cancer." European journal of Oncology nursing April 17(2): 176-183.

Kostagiolas, P., K. Martzoukou, G. Georgantzi and D. Niakas (2013). "Information seeking behaviour of parents of paediatric patients for clinical decision making: the central role of information literacy in a participatory setting." Information Research 18(3): Paper 590.

Lagan, B. M., M. Sinclair and G. Kernohan (2010). "Internet Use in Pregnancy Informs Women's Decision Making: A Web-Based Survey." Birth 37(2): 106-115.

Laing, A. and G. Hogg (2002). "Political exhortation, patient expectation and professional execution: perspectives on consumerization of health care." British Journal of Management 13(2): 173-188.

Liang, B. and D. L. Scammon (2011). "E-Word-of-Mouth on health social networking sites: An opportunity for tailored health communication." Journal of Consumer Behaviour 10(6): 322-331.

Longo, D. R., S. L. Schubert, B. A. Wright, J. LeMaster, C. D. Williams and J. N. Clore (2010). "Health Information Seeking, Receipt, and Use in Diabetes Self-Management." Annals of Family Medicine 8(4): 334-340.

Lye, A., W. Shao, S. Rundle-Thiele and C. Fausnaugh (2005). "Decision waves: consumer decisions in today's complex world." European Journal of Marketing 39(1/2): 216-230.

Martin, S. (2016). "Word-of-mouth in the health care sector: a literature analysis of the current state of research and future perspectives." International Review on Public and Nonprofit Marketing: 1-22.

McGoldrick, P. J. and N. Collins (2007). "Multichannel retailing: profiling the multichannel shopper." International Review of Retail, Distribution and Consumer Research 17(2): 139158.

Mesters, I., B. van den Borne, M. De Boer and J. Pruyn (2001). "Measuring information needs among cancer patients." Patient Education and Counseling 43(3): 253-262.

Mitra, K., M. C. Reiss and L. M. Capella (1999). "An examination of perceived risk, information search and behavioral intentions in search, experience and credence services." Journal of Services Marketing 13(3): 208-228.

Murray, K. B. (1992). "Health Care Service Decision Influences: An Exploratory Investigation of Search and Nonsearch Criteria for Professionals and Patients." Journal of Health Care Marketing 12(1): 24-38. 
Mutz, D. C. (2005). "Social Trust and E-Commerce Experimental Evidence for the Effects of Social Trust on Individuals' Economic Behavior." Public Opinion Quarterly 69(3): 393-416.

Neuberger, J. (2000). "The educated patient: new challenges for the medical profession." Journal of Internal Medicine 247: 6-10.

Niehues, S. M., M. Emmert, M. Haas, O. Schöffski and B. Hamm (2012). "The impact of the emergence of Internet hospital rating sites on patients' choice: a quality evaluation and examination of the patterns of approach." International Journal of Technology Marketing 7(1): 4-19.

Nocell, G., D. Romano and G. Stefani (2014). "Consumers' attitudes, trust and willingness to pay for food information." International Journal of Consumer Studies 38(2): 153-165.

Özer, Ö., U. Subramanian and Y. Wang (2017). "Information sharing, advice provision, or delegation: what leads to higher trust and trustworthiness?" Management Science.

Pandey, S. K., J. J. Hart and S. Tiwary (2003). "Women's health and the Internet: understanding emerging trends and implications." Social Science \& Medicine 56(1): 179-191.

Payne, A., K. Storbacka and P. Frow (2008). "Managing the co-creation of value." Journal of the Academy of Marketing Science 36(1): 83-96.

Percheski, C. and E. Hargittai (2011). "Health information-seeking in the digital age." Journal of American College Health 59(5): 379-386.

Pieniak, Z., W. Verbeke, J. Scholderer, K. Brunsø and S. O. Olsen (2007). "European consumers' use of and trust in information sources about fish." Food Quality and Preference 18: 1050-1063.

Rangaswamy, A. and G. H. Van Bruggen (2005). "Opportunities and challenges in multichannel marketing: An introduction to the special issue." Journal of Interactive Marketing 19(2): 5-11.

Rooks, R. N., J. C. Wiltshire, K. Elder, R. BeLue and L. C. Gary (2012). "Health information seeking and use outside of the medical encounter: is it associated with race and ethnicity?" Social Science \& Medicine 74(2): 176-184.

Rundle-Thiele, S. and R. Russell-Bennett (2010). "Patient influences on satisfaction and loyalty for GP services." Health marketing quarterly 27(2): 195-214.

Smith, D. (2011). "Health care consumer's use and trust of health information sources." Journal of Communication in Healthcare 4(3): 200-210. 
Snellman, K. (2014). "The Social Disparity Behind America's Growing Obesity Gap." Retrieved July 29, 2014, from https://hbr.org/2014/01/the-social-disparity-behind-americasgrowing-obesity-gap/.

Thiede, M. (2005). "Information and access to health care: is there a role for trust?" Social Science \& Medicine 61: 1452-1462.

Thompson, V. L. S. (2013). "Making decisions in a complex information environment: evidential preference and information we trust." BMC medical informatics and decision making 13(3): 1.

Tzempelikos, N. and S. Gounaris (2017). A Conceptual and Empirical Examination of Key Account Management Orientation and its Implications-The Role of Trust. The Customer is NOT Always Right? Marketing Orientationsin a Dynamic Business World, Springer: 673681.

Verhoef, P. C., S. A. Neslin and B. Vroomen (2007). "Multichannel customer management: Understanding the research-shopper phenomenon." International Journal of Research in Marketing 24(2): 129-148.

Waytz, A., J. Heafner and N. Epley (2014). "The mind in the machine: Anthropomorphism increases trust in an autonomous vehicle." Journal of Experimental Social Psychology 52: 113-117.

Williams, J. R. and P. J. Hensel (1991). "Changes in Physicians' Sources of Pharmaceutical Information: A Review and Analysis." Journal of Health Care Marketing 11(3): 46-60.

Wogalter, M. S., D. M. DeJoy and K. R. Laughery (1999). "Organizing theoretical framework: a consolidated communication-human information processing (C-HIP) model." Warnings and risk communication: 15-23.

Zaheer, A. and N. Venkatraman (1995). "Relational governance as an interorganizational strategy: An empirical test of the role of trust in economic exchange." Strategic management journal 16(5): 373-392.

Zainuddin, N., R. Russell-Bennett and J. Previte (2013). "The value of health and wellbeing : an empirical model of value creation in social marketing." European Journal of Marketing 47(9): 1504-1524. 